Article

\title{
Dispersion of Heat Flux Sensors Manufactured in Silicon Technology
}

\author{
Katir Ziouche *, Pascale Lejeune, Zahia Bougrioua and Didier Leclercq \\ Institute of Electronics, Microelectronics and Nanotechnology, University Lille 1 and CNRS; \\ Villeneuve d'Ascq 59652, France; pascale.lejeune@univ-lille1.fr (P.L.); \\ zahia.bougrioua@iemn.univ-lille1.fr (Z.B.); didier.leclercq@univ-lille1.fr (D.L.) \\ * Correspondence: katir.ziouche@univ-lille1.fr; Tel.: +33-3-20-19-78-39
}

Academic Editor: Stefano Mariani

Received: 25 April 2016; Accepted: 3 June 2016; Published: 9 June 2016

\begin{abstract}
In this paper, we focus on the dispersion performances related to the manufacturing process of heat flux sensors realized in CMOS (Complementary metal oxide semi-conductor) compatible 3-in technology. In particular, we have studied the performance dispersion of our sensors and linked these to the physical characteristics of dispersion of the materials used. This information is mandatory to ensure low-cost manufacturing and especially to reduce production rejects during the fabrication process. The results obtained show that the measured sensitivity of the sensors is in the range 3.15 to $6.56 \mu \mathrm{V} /\left(\mathrm{W} / \mathrm{m}^{2}\right)$, associated with measured resistances ranging from 485 to $675 \mathrm{k} \Omega$. The dispersions correspond to a Gaussian-type distribution with more than $90 \%$ determined around average sensitivity $\overline{S_{e}}=4.5 \mu \mathrm{V} /\left(\mathrm{W} / \mathrm{m}^{2}\right)$ and electrical resistance $\bar{R}=573.5 \mathrm{k} \Omega$ within the interval between the average and, more or less, twice the relative standard deviation.
\end{abstract}

Keywords: silicon; sensor; CMOS; heat flux; thermoelectric; dispersion

\section{Introduction}

Heat flux sensors allow to obtain a direct reading of the thermal transfers between a surface and its environment in a real-time manner. The balance of exchanged heat (received or supplied) that can be conductive, convective and radiative is expressed by means of the measured thermal flux (in $\mathrm{W} \cdot \mathrm{m}^{-2}$ ). The design requirements of the flux sensor are a very low thickness associated with a good thermal conductivity to be representative of the exchange between the surface on which the microsensor is placed and its surrounding environment. To fulfill these requirements and to envisage a large-scale development, we developed sensors in CMOS-compatible technology on silicon wafers which thickness is typically lower than $400 \mu \mathrm{m}$ and the thermal conductivity is pretty high $\left(\lambda_{t h}=140 \mathrm{~W} / \mathrm{m} \cdot \mathrm{K}\right)$. Another advantage of the microsensors we present lies in the simple relation between the thermal flux and the corresponding DC voltage measured by the thermopile of the heat flux sensor [1-4]. These sensors can be used in a large range of applications: contactless temperature measurement [4-7], evaporation of latent heat [8], and determination of dissipated thermal power [9]. Information related to the manufacturing process of the system is detailed in [10].

In this paper, we targeted a fine study of the sensor's reliability. The two main parameters that qualify the fabrication reliability of these large-area sensors (typically $5 \times 5 \mathrm{~mm}^{2}$ ) on a 3-in full plate are the sensitivity and the electrical resistance of the heat flux microsensor. The optimization of the fabrication process requires a fine control of the thicknesses, electric resistivities and thermoelectric powers of the thermoelectric materials. They are measured at each technological fabrication step. In spite of the limits of the 3-in technology, a very good reliability of our manufacturing process has been achieved with an associated Gaussian dispersion of the sensitivity and electrical resistance values. We also show that the measured sensitivities are in a good agreement with those computed 
by a dedicated mathematical model [10]. In Section 2, we detail the design of the sensor and the modelling of the structure. The fabrication of the sensor, related experiments and the discussion are then presented in the Section 3.

\section{Sensor Design and Modeling}

\subsection{Sensor Description}

The originality of the sensor consists of a thermal asymmetry due to the use of porous silicon trenches in a silicon wafer. Compared to silicon $\left(\lambda_{S i} \sim 140 \mathrm{~W} / \mathrm{m} \cdot \mathrm{K}\right)$, porous silicon presents a thermal conductivity 100 times lower $\left(\lambda_{\text {Porous } S i} \sim 1.2\right.$ to $\left.2 \mathrm{~W} / \mathrm{m} \cdot \mathrm{K}\right)$ [11-13]. When a transverse heat flux $\varphi$ flows through the sensor, this asymmetry leads to lateral periodic temperature variations $\Delta \mathrm{T}$ inside the sensor (Figure 1).

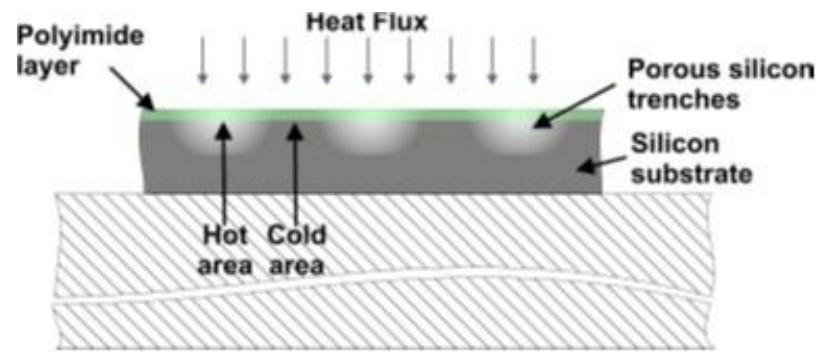

Figure 1. Cross-sectional view of periodic temperature variations induced by the heat flux.

A gold/polysilicon thermopile, made of $\mathrm{N}$ thermocouples correctly arranged as shown in Figure 2, transforms these gradients of temperature into a Seebeck voltage:

$$
\mathrm{V}=\mathrm{N} \alpha \Delta \mathrm{T}
$$

where $\alpha(\mu \mathrm{V} / \mathrm{K})$ is the Seebeck coefficient of the thermocouples.

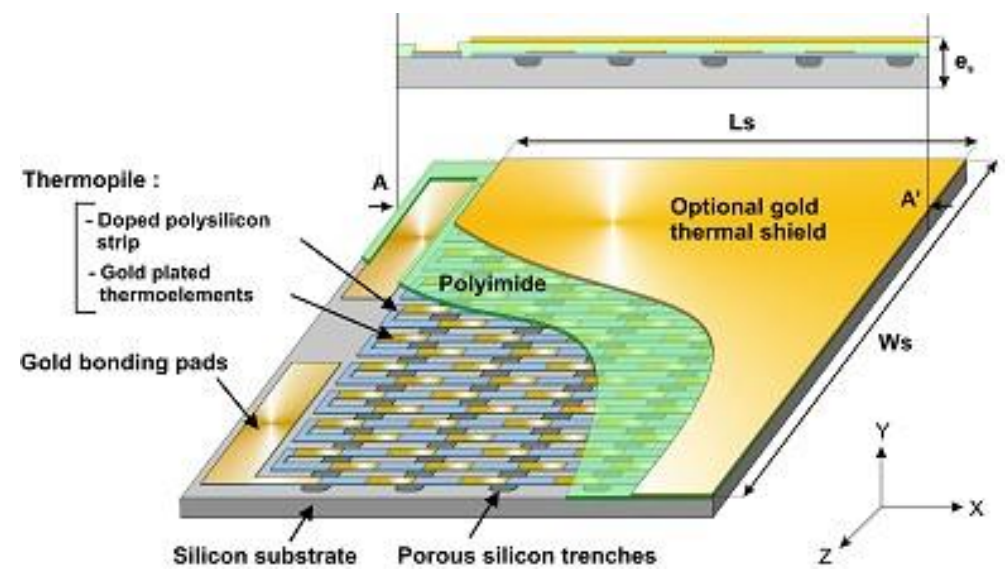

Figure 2. Schematic diagram of the heat flux microsensor.

Assuming the Fourier law [14], a coefficient $r_{t h}$ considered as a two-dimensional (2D) thermal resistance between two successive junctions can be expressed by

$$
\mathrm{r}_{\mathrm{th}}=\frac{\Delta \mathrm{T}}{\varphi}\left(\mathrm{Km}^{2} / \mathrm{W}\right)
$$


This thermal coefficient is a function of the structural dimensions and thermal conductivities of the different parts and layers constituting the sensor and is determined by using numerical modelling [10]. The sensitivity of the microsensor to a heat flux is given by

$$
\mathrm{S}_{\mathrm{e}}=\frac{\mathrm{dV}}{\mathrm{d} \varphi}=\mathrm{N} \alpha \mathrm{r}_{\mathrm{th}}=\alpha \frac{\mathrm{A}_{\mathrm{S}}}{(\mathrm{w}+\mathrm{i})} \frac{\mathrm{r}_{\mathrm{th}}}{\mathrm{L}}\left(\mathrm{Vm}^{2} \mathrm{~W}^{-1}\right)
$$

where $A_{s}$ is the surface of the sensor, $L$ is the length of a thermocouple, $w$ and $i$ are, respectively, the width of the strips and interstrip of the thermopile (Figure 2).

The electrical resistance $R_{e l}$ of the thermopile which is made of a polysilicon track partially covered by gold strips is

$$
\mathrm{R}_{\mathrm{el}}=\mathrm{N}\left(\frac{\rho_{\text {poly }} \mathrm{L}}{2 \mathrm{e}_{\text {poly }} \mathrm{w}}+\frac{\rho_{\text {poly }} \rho_{\mathrm{Au}} \mathrm{L}}{2\left(\rho_{\mathrm{Au}} \mathrm{e}_{\text {poly }}+\rho_{\text {poly }} \mathrm{e}_{\mathrm{Au}}\right) \mathrm{w}}\right)
$$

with $e_{\text {poly }}, e_{A u}$ and $\rho_{\text {poly }}, \rho_{A u}$, respectively, the thicknesses and the electrical resistivities for the polysilicon tracks and gold strips.

\subsection{Thermal Modeling}

A numerical model was developed, using COMSOL multiphysics software (COMSOL ${ }^{\mathrm{TM}}$ Multiphysics), to optimize the geometrical dimensions of the sensors [10].

As shown in Equation (3), the sensitivity to the heat flux density, $S_{e}$, is proportional to $r_{t h} / L$. So, to determine the optimal width of the porous trenches $w_{\text {por }}$ according to the thermocouple length $L$ (Figure 3), the evolution of $r_{t h} / L$ is studied versus the ratio $w_{\text {por }} / L$ (from 0 to 1 ) for different values of lengths $L$ (from 100 to $1000 \mu \mathrm{m}$ ) and depths $d_{\text {por }}$ (from 50 to $300 \mu \mathrm{m}$ ). It is demonstrated that the maximum values of $r_{t h} / L$ are systematically obtained for the same ratio $w_{\text {por }} / L=0.9$, whatever the depth of the porous silicon box and the length of the thermocouple.

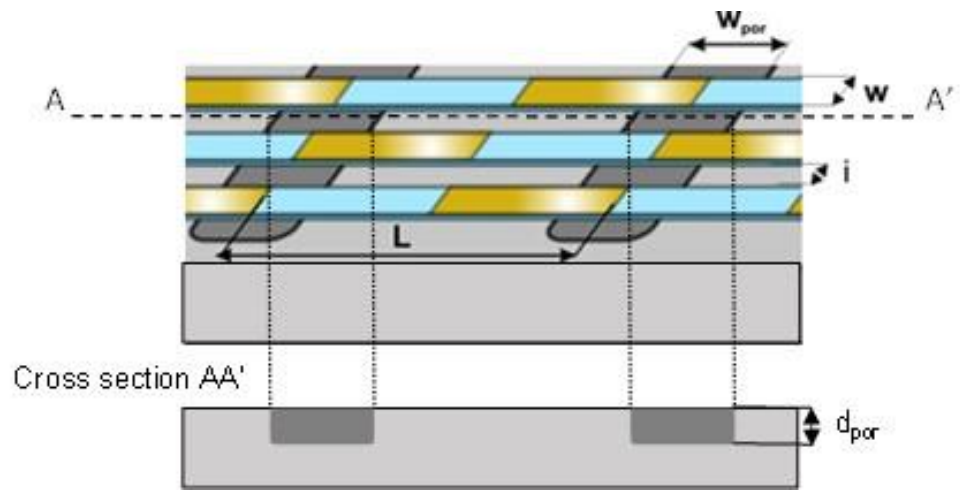

Figure 3. Zoom on an elementary cell of the heat flux microsensor.

In these conditions, the maximum values of $r_{t h} / L$ as a function of the cell length $L$ for different depths $d_{\text {por }}$ of porous silicon boxes are represented in Figure 4.

One can observe that the maximum value of $r_{t h} / L(0.14 \mathrm{~K} \cdot \mathrm{m} / \mathrm{W})$ that corresponds to an optimal sensitivity, is obtained for $L=500 \mu \mathrm{m}$ and $d_{\text {por }}=300 \mu \mathrm{m}$. In fact, in practice, the depth $d_{\text {por }}$ cannot exceed $150 \mu \mathrm{m}$ because of the weak mechanical resistance of porous silicon. For a sensor with a width set to $5 \mathrm{~mm}$, the optimum values of the widths of the strips and interstrips of the thermopile are, respectively, $w=80 \mu \mathrm{m}$ and $i=20 \mu \mathrm{m}$. The corresponding polysilicon thickness is $e_{\text {poly }}=0.6 \mu \mathrm{m}$.

So, to summarize, the geometrical dimensions kept to fabricate the microsensors on a 3-in wafer are: $L=500 \mu \mathrm{m}, e_{\text {poly }}=600 \mathrm{~nm}, w=80 \mu \mathrm{m}$ and $i=20 \mu \mathrm{m}$. 


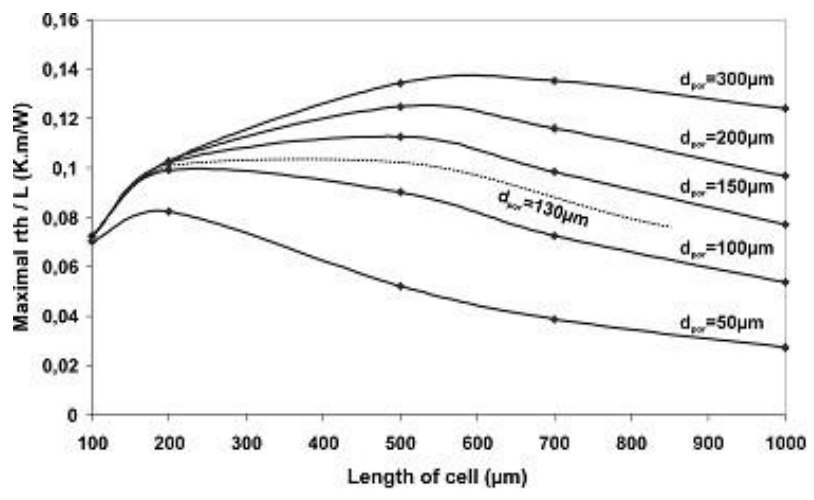

Figure 4. Values of $r_{t h} / L$ versus cell length for different depths of porous silicon trenches for $w_{\text {por }} / L=0.9$.

\section{Experimental Results and Discussion}

\subsection{Sensor Fabrication}

The sensitivity $S_{e}$ depends mainly on $d_{p o r}$ and $w_{p o r}$ (the depth and width of the porous silicon boxes) and on $\alpha$ (the Seebeck coefficient of thermocouples). The electrical resistance $R_{e l}$ depends primarily on the thicknesses $e_{\text {poly }}, e_{A u}$ and electrical resistivities $\rho_{p o l y}, \rho_{A u}$ of the polysilicon track and gold strips of the thermoelectric layer (Equation (4)). Thus, these parameters were particularly controlled during the fabrication process. The porous silicon trenches are processed onto 3-in-diameter $<100>$ silicon wafers (thickness is $380 \pm 25 \mu \mathrm{m}$, p-type doping with Bore and electrical resistivity between 0.009 and $0.01 \Omega . c m$ ). The wafers were patterned and anodized (Figure $5 \mathrm{a}$ ) in a double cell tank (Figure $5 b$ ) during several minutes in a mixture of $27 \%$ fluorhydric acid (HF), $38 \%$ water and $35 \%$ ethanol with a current density of $100 \mathrm{~mA} / \mathrm{cm}^{2}$ [15].

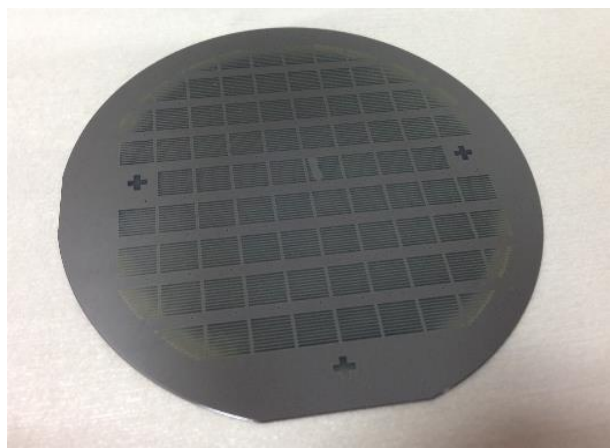

(a)

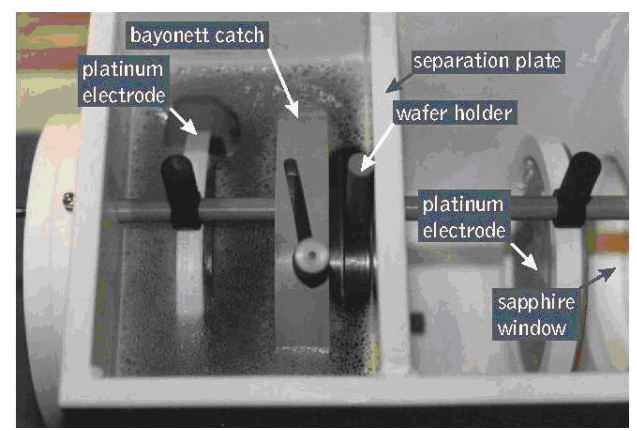

(b)

Figure 5. (a) Photography of a 3-in-diameter silicon wafer with processed porous silicon trenches; (b) Double cell HF tank for porous silicon etching with electrolytic backside contact $\left(\mathrm{AMMT}^{\mathrm{TM}}\right)$.

The engraving speed is approximately 4 to $5 \mu \mathrm{m}$ per minute. The anodization of silicon lasts about $25 \mathrm{~min}$, resulting in boxes with depths that varies from $100 \mu \mathrm{m}$ on the center of the wafer to $130 \mu \mathrm{m}$ on the edges (measured by scanning electron microscopy). These edge effects are mainly due to the dimensions of the wafer $(3 \mathrm{in})$ which are smaller than those of the electrodes $(4$ inch, Figure $5 b)$. So, the electric lines of current which pass from an electrode to the other one through the wafer undergo a deviation which generates a stronger concentration of the lines in the periphery of the wafer, locally inducing the over-engraving. The polysilicon layer was in situ n-type doped with Phosphorus during its deposition by LPCVD (low pressure chemical vapor deposition). The thermopile zigzag-shaped track was realized by lithography and mesa etching using reactive ion etching with $\mathrm{SF}_{6}$ and $\mathrm{CF}_{4}$ mixture gas. The periodical plated thermoelements were processed by lift-off techniques using 
the evaporation of a Ti/Au bilayer. The in-plane electrical properties of the polysilicon layer were characterized by Van der Pauw and Hall effect methods. The Seebeck coefficient of the thermocouple was measured on equivalent layers with an experimental set-up [16].

Table 1 presents the range of values for the electrical resistivity $\rho_{\text {poly }}$, thermoelectric coefficient $\alpha$ and thickness $e_{\text {poly }}$ of the polysilicon layer measured in different locations of the wafer [16]. The thickness $e_{A u}$ of the Ti/Au bilayer is $250 \mathrm{~nm} \pm 10 \mathrm{~nm}$. Because of its very low electrical resistivity, this layer has a minor impact on the value of the electrical resistance of the thermopile (Equation (4)).

Table 1. Range of values for electrical resistivity $\rho_{\text {poly }}$, thermoelectric coefficient $\alpha$ and thickness $e_{\text {poly }}$ of the polysilicon layer.

\begin{tabular}{cccc}
\hline & $\rho_{\text {poly }}(\mathrm{m} \Omega \cdot \mathrm{cm})$ & $\alpha(\mu \mathrm{V} / \mathrm{K})$ at 298 K & $\boldsymbol{e}_{\text {poly }}(\mathrm{nm})$ \\
\hline Dispersion & $0.0205-0.024$ & $220-260$ & $570-620$ \\
\hline
\end{tabular}

\subsection{Sensor Characterizations}

A set of five masks was used for the fabrication of the sensors on a complete 3-in wafer. First of all, the positions of the efficient heat flux sensors on the wafer were established. Then, the sensitivities and electrical resistances of the 74 efficient sensors were measured: the values are given in Table 2. The sensitivities $S_{e}$ of the heat flux sensors were determined by the radiative method. The calibration is described in [10]. These sensors do not need cooling. They can operate from ambient temperature up to $200{ }^{\circ} \mathrm{C}$.

Table 2. Sensors' sensitivities and electrical resistances measured on a complete 3 in wafer.

\begin{tabular}{|c|c|c|c|c|c|c|c|c|c|c|c|}
\hline Lign & Column & 1 & 2 & 3 & 4 & 5 & 6 & 7 & 8 & 9 & 10 \\
\hline \multirow{3}{*}{1} & Sensor number & & & 1 & 2 & 3 & 4 & 5 & 6 & & \\
\hline & $R(k \Omega)$ & & & 637 & 570 & 580 & 675 & 570 & 557 & & \\
\hline & $\operatorname{Se}\left(\mu V /\left(W / m^{2}\right)\right)$ & & & 2 & 3.9 & 3.39 & 3.9 & 3.23 & 2.02 & & \\
\hline \multirow{3}{*}{2} & Sensor number & & 7 & 8 & 9 & 10 & 11 & 12 & 13 & 14 & \\
\hline & $R(k \Omega)$ & & 548 & 560 & 570 & 570 & 589 & 657 & 620 & 584 & \\
\hline & $\operatorname{Se}\left(\mu V /\left(W / m^{2}\right)\right)$ & & 4.59 & 3.47 & 5.44 & 4.5 & 4.2 & 4.15 & 3.44 & 3.32 & \\
\hline \multirow{3}{*}{3} & Sensor number & 15 & 16 & 17 & 18 & 19 & 20 & 21 & 22 & 23 & 24 \\
\hline & $R(k \Omega)$ & 577 & 573 & 571 & 569 & 590 & 550 & 530 & 588 & 625 & 597 \\
\hline & $\operatorname{Se}\left(\mu V /\left(W / m^{2}\right)\right)$ & 3.54 & 5.73 & 3.97 & 3.91 & 3.86 & 4 & 4.5 & 4.63 & 4.76 & 3.24 \\
\hline \multirow{3}{*}{4} & Sensor number & 25 & 26 & 27 & 28 & 29 & 30 & 31 & 32 & 33 & \\
\hline & $R(k \Omega)$ & 547 & 570 & 550 & 538 & 620 & 570 & 565 & 612 & 590 & - \\
\hline & $\operatorname{Se}\left(\mu V /\left(W / m^{2}\right)\right)$ & 6.46 & 5.3 & 4.78 & 4.12 & 3.9 & 4.17 & 4.12 & 4.3 & 4.46 & \\
\hline \multirow{3}{*}{5} & Sensor number & & 34 & 35 & 36 & 37 & 38 & 39 & 40 & 41 & \\
\hline & $R(k \Omega)$ & & 552 & 435 & 530 & 545 & 490 & 573 & 580 & 620 & \\
\hline & $\operatorname{Se}\left(\mu V /\left(W / m^{2}\right)\right)$ & & 6.13 & 4.3 & 4.45 & 4.1 & 4.12 & 4.29 & 4.64 & 5.24 & \\
\hline \multirow{3}{*}{6} & Sensor number & 42 & 43 & 44 & 45 & 46 & 47 & 48 & 49 & 50 & 51 \\
\hline & $R(k \Omega)$ & 537 & 535 & 278 & 554 & 535 & 525 & 485 & 596 & 604 & 620 \\
\hline & $\operatorname{Se}\left(\mu V /\left(W / m^{2}\right)\right)$ & 6.56 & 5.57 & 2.35 & 4.54 & 4.19 & 4.23 & 4.2 & 4.23 & 4.49 & 6.02 \\
\hline \multirow{3}{*}{7} & Sensor number & 52 & 53 & 54 & 55 & 56 & 57 & 58 & 59 & 60 & 61 \\
\hline & $R(k \Omega)$ & 136 & 556 & 556 & 564 & 531 & 546 & 555 & 606 & 588 & 585 \\
\hline & $\mathrm{Se}\left(\mu V /\left(W / m^{2}\right)\right)$ & 3 & 5.57 & 4.56 & 4.38 & 4.1 & 4.15 & 4.53 & 4.35 & 4.94 & 5 \\
\hline \multirow{3}{*}{8} & Sensor number & & 62 & 63 & 64 & 65 & 66 & 67 & 68 & & \\
\hline & $R(k \Omega)$ & & 550 & 575 & 561 & 350 & 585 & 585 & 605 & - & \\
\hline & $\operatorname{Se}\left(\mu V /\left(W / m^{2}\right)\right)$ & & 5.84 & 4.49 & 4.49 & 2.8 & 4.9 & 4.9 & 4.24 & & \\
\hline \multirow{3}{*}{9} & Sensor number & & & 69 & 70 & 71 & 72 & 73 & 74 & & \\
\hline & $R(k \Omega)$ & & & 557 & 516 & 574 & 584 & 598 & 600 & & \\
\hline & $\operatorname{Se}\left(\mu V /\left(W / m^{2}\right)\right)$ & & & 2.35 & 5.7 & 5.2 & 5.2 & 4.52 & 1.57 & & \\
\hline
\end{tabular}


A first analysis of these results shows that, for the four sensors situated at the four corners of Table 2 (nbr 1, nbr 6, nbr 69 and nbr 74), the sensitivity $S_{e}$ is very low because of incomplete porous silicon boxes, as shown in Figure 5a. This is caused by the mark left by the seal glued onto the wafer during the electrolysis. The seal is used to isolate the electrolytes of the two tanks in order to avoid electric current leaks. One can also find a few other low values of electrical resistances that are due to contacts resulting in shunts between two adjacent strips of the thermopile (nbr 44, nbr 52 and nbr 65). These kinds of problems can occur during different steps in the fabrication process: lithography, polysilicon engraving or lift-off of the Ti/Au layer which is the second material of the thermopile. We can mention here the challenge of fabricating 500 strips that are $5 \mathrm{~mm}$ long and spaced $20 \mu \mathrm{m}$ apart.

When only considering the 67 reliable sensors, one finds that the measured sensitivities vary between 3.15 and $6.56 \mu \mathrm{V} /\left(\mathrm{W} / \mathrm{m}^{2}\right)$ and, that the measured resistance values lie between 485 and $675 \mathrm{k} \Omega$. The average values of sensitivity and electrical resistance are respectively $\overline{S_{e}}=4.5 \mu \mathrm{V} /\left(\mathrm{W} / \mathrm{m}^{2}\right)$ and $\bar{R}=573.5 \mathrm{k} \Omega$. The global dispersions of both parameters are given in Figure 6 . The two histograms exhibit Gaussian-type distributions. From these results the calculated standard deviations are, respectively, $\sigma_{S e}=0.74 \mu \mathrm{V} /\left(\mathrm{W} / \mathrm{m}^{2}\right)$ and $\sigma_{R}=34.8 \mathrm{k} \Omega$. Furthermore, $95.6 \%$ of the sensitivity values are within the interval $\left[\overline{S_{e}}-2 \sigma_{S e} ; \overline{S_{e}}+2 \sigma_{S e}\right]$ and $73.5 \%$ in $\left[\overline{S_{e}}-\sigma_{S e} ; \overline{S_{e}}+\sigma_{S e}\right]$. Similarly, 94.3\% of the resistances are in the range $\left[\bar{R}-2 \sigma_{R} ; \bar{R}+2 \sigma_{R}\right]$ and $74.3 \%$ in $\left[\bar{R}-\sigma_{R} ; \bar{R}+\sigma_{R}\right]$.

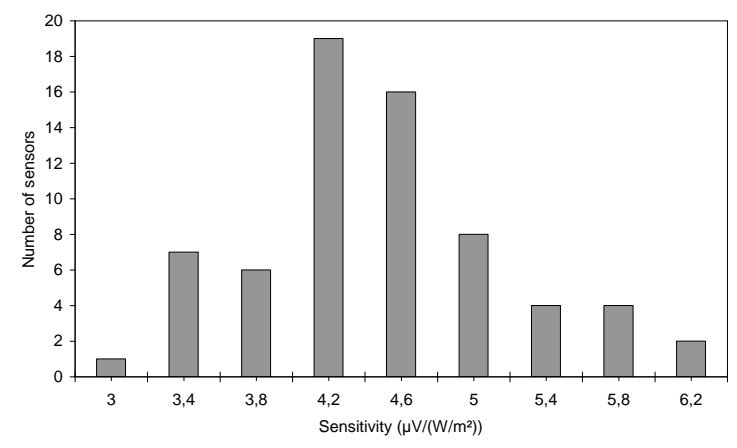

(a)

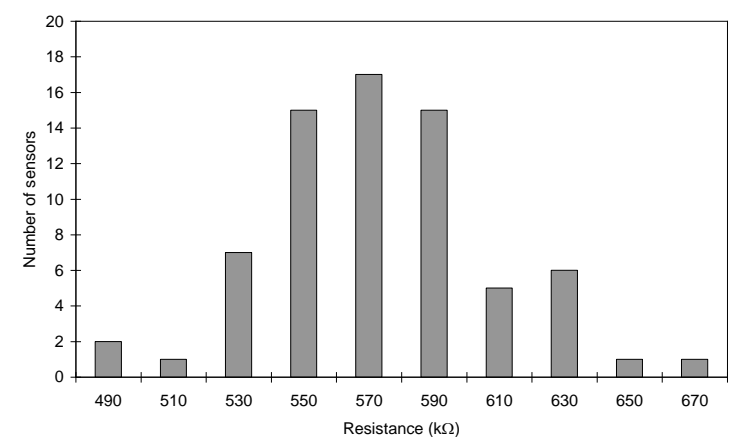

(b)

Figure 6. Dispersion histograms of (a) sensitivities; and (b) resistances.

\subsection{Discussion}

As stated before the depth of the porous silicon boxes $d_{p o r}$ is between $100 \mu \mathrm{m}$ and $130 \mu \mathrm{m}$. The corresponding thermal coefficient $r_{t h}$ is deduced from numerical model curves (Figure 4 ) and the ratio $r_{t h} / L$ lies between 0.088 and $0.101 \mathrm{~K} \cdot \mathrm{m} / \mathrm{W}$.

By introducing these values of $r_{t h} / L$ and the thermoelectric coefficient $\alpha$ given in Table 1 in Equation (3), the calculated sensitivity can be evaluated between 4.84 and $6.57 \mu \mathrm{V} /\left(\mathrm{W} / \mathrm{m}^{2}\right)$. So the calculated sensitivity range cross the experimental range $\left[\overline{S_{e}}-\sigma_{S e} ; \overline{S_{e}}+\sigma_{\text {Se }}\right]$ (i.e., $\left.3.76-5.24 \mu \mathrm{V} /\left(\mathrm{W} / \mathrm{m}^{2}\right)\right)$ and encompass the experimental average value $\left(4.5 \mu \mathrm{V} /\left(\mathrm{W} / \mathrm{m}^{2}\right)\right)$. There is a slight shift in the measured values.

In the same way, the electrical resistances are calculated by using Equation (4). The contact resistances between the polysilicon layer and the $(\mathrm{Ti} / \mathrm{Au})$ bilayer are measured by the transmission line method (TLM) and the Van Der Pauw method. It is approximately $7 \Omega$ for each thermocouple, corresponding to few $\mathrm{k} \Omega$ for the sensor, and it can therefore be neglected. Consequently, with the minimal and maximal values of $\rho_{\text {poly }}$ and $e_{\text {poly }}$ given in Table 1 , the theoretical values of the total resistance vary between 517 and $658 \mathrm{k} \Omega$. The comparison to the measured values, which range between 538.7 and $608.3 \mathrm{k} \Omega$ (average value of $573.5 \mathrm{k} \Omega$ ), is quite good.

The good agreement observed between the theoretical and measured values demonstrates the performance and the reliability of the fabrication process. Actually the electrical resistances and sensitivities of the sensors are higher at the periphery of the wafer. The values of the sensitivities are 
explained by the greater thickness of the porous silicon boxes and the higher thermoelectric power at this location of the wafer. A lower sensitivity for some peripheral sensors is due to an incomplete manufacturing of the corresponding porous silicon boxes. Concerning the values of the electrical resistances, the variations are essentially due to a local lower thickness of the polysilicon and to a higher resistivity.

\section{Conclusions}

In this paper, a study of the performance and reliability of heat flux microsensors fabricated by means of technological processes and equipment suited to 3-in wafers has been proposed. In particular, we show that the dispersion observed in terms of sensitivity and electrical resistance is closely related to the limits of the equipment and of the processes used. Actually, the 3-in processes do not allow obtaining homogeneous coats on 3-in wafers (two sizes above needed). The LPCVD technique allows achieving a thickness of polysilicon with fluctuations of about $\pm 5 \%$. The resistivity and the thermoepower bound to the doping level are not homogeneous, with fluctuations of about $\pm 8 \%$. A doping by implanting should allow a better homogeneity than the doping in situ. The anodization process entails a difference in the thickness of porous silicon between the center and the periphery of the wafer which is translated to a difference in sensitivity of $10 \%$. This value can be reduced by increasing the distance separating the electrodes of the wafer.Finally, it has been shown that differences between the values of sensors' sensitivities in the periphery of the wafer are mainly due to edge effects. If we consider the results obtained for the sensors located in an area of about 2-in in diameter centred on the wafer, the dispersion is much better: with $80 \%$ of the sensitivities within the interval $\overline{S_{e}}-2 \sigma_{S e}, \overline{S_{e}}+2 \sigma_{S e}$ where $S e=4.46 \mu \mathrm{W} /\left(\mathrm{W} / \mathrm{m}^{2}\right)$ and $\sigma_{S e}=0.44 \mu \mathrm{W} /\left(\mathrm{W} / \mathrm{m}^{2}\right)$. These results altogether highlight the reliability and maturity of the technology process. The heat flux microsensors are therefore a viable solution for applications outside a laboratory environment.

Acknowledgments: This work was supported by "Bpifrance" in the frame of the "Open Food System Project". It was also partly supported by the French RENATECH network.

Author Contributions: K. Ziouche and D. Leclercq conceived and designed the experiments; K. Ziouche and P. Lejeune performed the experiments; K. Ziouche and Z. Bougrioua contribute the materials and analysis tools; all the authors analyzed the data and wrote the manuscript.

Conflicts of Interest: The authors declare no conflict of interest.

\section{References}

1. Lenggenhager, R.; Baltes, H.; Elbel, T. Thermoelectric infrared sensors in CMOS technology. Sens. Actuators A Phys. 1993, 14, 216-220. [CrossRef]

2. Sion, C.; Godts, P.; Ziouche, K.; Bougrioua, Z.; Lasri, T.; Leclercq, D. Unpackaged infrared thermoelectric microsensor realized on suspended membrane by silicon technology. Sens. Actuators A Phys. 2012, 175, 78-86. [CrossRef]

3. Zhou, H.; Kropelnicki, P.; Tsai, J.M.; Lee, C. Development of a thermopile infrared sensor using stacked double polycrystalline silicon layers based on the CMOS process. J. Micromech. Microeng. 2013. [CrossRef]

4. Boutchich, M.; Ziouche, K.; Ait-Hammouda Yala, M.; Godts, P.; Leclercq, D. Package free infrared microsensor using thermopile. Sens. Actuators A Phys. 2005, 121, 52-58. [CrossRef]

5. De Vrient, A.B. La Transmission de la Chaleur, 3rd ed.; Morin, G., Ed.; Boucherville, QC, Canada, 1992; Volume 2.

6. Ziouche, K.; Godts, P.; Leclercq, D. Polyimid resist as infrared absorbing layer for radiation microsensors. Sens. Mater. 2000, 12, 445-454.

7. Ziouche, K.; Boutchich, M.; Bernard, D.; Godts, P.; Leclercq, D. A New Ultra-Violet Microradiometer. In Proceedings of the International Frequency Sensor Association, Nuremberg, Germany, 9 May 2001.

8. Godts, P.; Dupont, D.; Leclercq, D. Direct measurement of the latent heat of evaporation by flowmetric method. IEEE Trans. Instrum. Meas. 2005, 54, 2364-2369. [CrossRef] 
9. Mancier, V.; Leclercq, D. Power dissipated measurement of an ultrasonic generator in a viscous medium by flowmetric method. Ultrason. Sonochem. 2008, 15, 973-980. [CrossRef] [PubMed]

10. Ziouche, K.; Godts, P.; Bougrioua, Z.; Sion, C.; Lasri, T.; Leclercq, D. Quasi-monolithic heat-flux microsensor based on porous silicon boxes. Sens. Actuators A Phys. 2010, 164, 35-40. [CrossRef]

11. Drost, A.; Steiner, P.; Moser, H.; Lang, W. Thermal conductivity of porous silicon. Sens. Mater. 1995, 7, 111-120.

12. Benedetto, G.; Boarino, L.; Brunetto, N.; Rossi, A.; Spagnolo, R.; Amato, G. Thermal properties of porous silicon layers. Philos. Mag. Part B 1997, 76, 383-393. [CrossRef]

13. Ziouche, K.; Bougrioua, Z.; Lejeune, P.; Lasri, T.; Leclercq, D. Probing Technique for Localized Thermal Conductivity Measurement. Meas. Sci. Technol. 2015. [CrossRef]

14. Özisik, M.N. Heat Conduction; John Wiley and Sons: New York, NY, USA, 1993.

15. Lysenko, V.; Roussel, P.; Remaki, B.; Delhomme, G.; Dittmar, A.; Barbier, D.; Martelet, C.; Strikha, V.; Boarino, L.; Bertola, M.; et al. Formation of thick oxidized meso porous silicon layers with low thermal conductivity for thermal isolation applications. In Proceedings of the Therminic'98, International Workshop on Thermal Investigations of IC's and Microstructures, Cannes, France, 28 September 1998; pp. 51-56.

16. Boutchich, M.; Ziouche, K.; Godts, P.; Leclercq, D. Characterization of Phosphorus and Boron Heavily. IEEE Electron Device Lett. 2002, 23, 139-141. [CrossRef]

(C) 2016 by the authors; licensee MDPI, Basel, Switzerland. This article is an open access article distributed under the terms and conditions of the Creative Commons Attribution (CC-BY) license (http:/ / creativecommons.org/licenses/by/4.0/). 